\title{
Mitoxantrone slowed progression of disability and reduced relapses in multiple sclerosis
}

Hartung HP, Gonsette R, König N, et al. Mitoxantrone in progressive multiple sclerosis: a placebo-controlled, double-blind, randomised, multicentre trial. Lancet 2002;360:2018-25.

\section{QUESTION: In patients with worsening relapsing remitting or secondary progressive multiple sclerosis (MS), is mitoxantrone effective for slowing progression of disability and reducing relapses?}

\section{Design}

Randomised (allocation concealed*), blinded (patients and outcome assessors),* placebo controlled trial with 24 months of follow up.

\section{Setting}

17 centres in Belgium, Germany, Hungary, and Poland.

Patients

194 patients $18-55$ years of age who had worsening relapsing-remitting or secondary progressive MS. Additional inclusion criteria included Kurtzke Expanded Disability Status Scale (EDSS) score 3.0-6.0 and worsening by $\geq 1$ EDSS point during the 18 months before enrolment. 188 patients (97\%) (mean age 40 y, 52\% women) completed follow up.

\section{Intervention}

Patients were allocated to mitoxantrone, $12 \mathrm{mg} / \mathrm{m}^{2}$ $(\mathrm{n}=63), 5 \mathrm{mg} / \mathrm{m}^{2}(\mathrm{n}=66)$, or placebo $(\mathrm{n}=65)$ administered intravenously every 3 months for 24 months. By design, only patients in the mitoxantrone $12 \mathrm{mg}$ and placebo groups were included in the primary analysis.

\section{Main outcome measures}

The primary outcome was a composite of 5 clinical measures, including change from baseline EDSS at 24 months, change from baseline ambulation index at 24 months, number of relapses treated with corticosteroids, time to first treated relapse, and change from baseline standardised neurological status at 24 months, tested in 1 combined hypothesis of stochastic ordered alternatives.

\section{Main results}

Analysis was by intention to treat. Progression of disability was slower, and number of relapses fewer in the mitoxantrone $12 \mathrm{mg}$ group than in the placebo group (assessed on the composite outcome as well as on the individual components) (table).

\section{Conclusion}

In patients with worsening relapsing-remitting or secondary progressive multiple sclerosis, mitoxantrone was effective for slowing progression of disability and reducing relapses.

*See glossary.

\section{COMMENTARY}

Current MS treatments have limited effect on patients who have entered a progressive phase of the disease. Therefore, a promising new treatment evokes great interest and explains the early release of such a drug for the treatment of these patients. The well designed, industry funded trial by Hartung et al shows that mitoxantrone can slow the progression and reduce the number of relapses over a 2 year period. This finding may provide an option when firstline disease modifying drugs, $\beta$ interferons and glatiramer acetate, fail or are inadequate. It would be most important to have an effect on progression of MS, but the effect in this study was greater on relapses $(\mathrm{p}<0.001)$ than on progression $(\mathrm{p}=0.019$ for EDSS, and $\mathrm{p}=0.031$ for the ambulation index).

Despite some initial enthusiasm in the MS community for the early trial results of mitoxantrone, there are serious limitations to the use of this drug. Firstly, the therapeutic effect is modest. It has substantial but manageable side effects during the infusions. Secondly, serious dose related cardiac effects limit its use to about the 24 months covered by this trial. The cardiac effects can be permanent, and patients must have cardiac monitoring of ejection fraction and other variables before and during treatment. Thus, selection and supervision of patients undergoing treatment should be done by an experienced neurology and cardiology team.

Although the authors have shown benefit in the 2 years when the drug can be used, what happens next? Does this short term treatment have worthwhile long term benefit? Once the dose limit has been reached or serious cardiac effects have developed, what do we have to offer the patient? MS is a chronic disease, and the long term benefit of a partially effective, potentially toxic, short term treatment requires evaluation beyond a 24 month clinical trial. A minimum suggestion would be to follow all patients in this trial annually to determine the time to wheelchair to see if the limited course of therapy has any lasting worthwhile effect.

T Jock Murray, MD Dalhousie University Halifax, Nova Scotia, Canada
Source of funding:

Wyeth-Lederle.

For correspondence:

Professor HP Hartung,

Heinrich-Heine-

Universität, Düsseldorf,

Germany.

hans-peter.hartung@

uni-duesseldorf.de

Abstract and

commentary also

appear in $A C P$

Journal Club.
Mitoxantrone $\left(12 \mathrm{mg} / \mathrm{m}^{2}\right)$ v placebo in relapsing-remitting or secondary progressive multiple sclerosis at 24 months $\dagger$

\begin{tabular}{|c|c|c|c|c|}
\hline Outcomes & Mitoxantrone & Placebo & $\begin{array}{l}\text { Mann-Whitney } \\
\text { difference }(95 \% \mathrm{CI})\end{array}$ & p Value $\ddagger$ \\
\hline Global difference in composite outcome & - & - & $0.30(0.17$ to 0.44$)$ & $<0.001$ \\
\hline Mean change from baseline in EDSS score & -0.13 & 0.23 & $0.24(0.04$ to 0.44$)$ & 0.019 \\
\hline Mean change from baseline in AIN score & 0.30 & 0.77 & $0.21(0.02$ to 0.40$)$ & 0.031 \\
\hline Mean change from baseline in SNS score & -1.07 & 0.77 & $0.23(0.03$ to 0.43$)$ & 0.027 \\
\hline Number of treated relapses & 24.08 & 76.77 & $0.39(0.18$ to 0.59$)$ & $<0.001$ \\
\hline Median time to first treated relapse (mo) & $\mathrm{N} / \mathrm{R}$ & 14.19 & $0.44(0.20$ to 0.69$)$ & $<0.001$ \\
\hline
\end{tabular}

†AIN = ambulation index; EDSS = Expanded Disability Status Scale; N/R = not reached in 24 months; SNS = standardised neurological status; composite outcome $=$ EDSS, AIN, SNS, number of treated relapses, and time to first treated relapse. Cl defined in glossary.

‡All significant differences favour mitoxantrone. 